\title{
Diálogos entre Imagem, Sujeito Pescador Artesanal, Sujeito Pesquisador em Etnomatemática ${ }^{1}$ \\ (Dialogues between Image, Subject Artisanal Fisherman, Subject Researcher in Ethnomatematics)
}

\author{
JUCIARA GUIMARÃES CARVALHO² e CLAUDIA GLAVAM DUARTE ${ }^{3}$ \\ ${ }^{2}$ Universidade Federal de Santa Catarina (juciara.guimaraes@ hotmail.com) \\ 3 Universidade Federal do Rio Grande do Sul - Campus Litoral Norte \\ (claudiaglavam@hotmail.com)
}

\begin{abstract}
Resumo. Este artigo tem como propósito articular o uso de imagens, como sendo um dispositivo, para potencializar o pensamento quando se realiza o ato de pesquisar. Em um primeiro momento, situamos as principais contribuições teóricas filosóficas de Wittgenstein e Foucault. Estaremos no apoiando nas noções wittgensteinianas de forma de vida, jogos de linguagem, regras de significações, semelhanças de família e nas noções foucaultianas de poder-saber. Em seguida, realizamos a prática de olhar inspiradas pelas obras de Rodrigo Dias Pereira para então tecermos alguns entendimentos envolvendo a imagem como potência problematizadora para a pesquisa.

Abstract. This article aims to articulate the use of images, as a device to enhance the thinking when performing the act of searching. At first, we place the main philosophical theoretical contributions of Wittgenstein and Foucault. We will be supporting in the Wittgensteinian notions of life form, language games, rules of meanings, family resemblances and in Foucault's notions of power-knowledge. Then perform the practice of looking inspired by the works of Rodrigo Dias Pereira and then we may weave some understandings involving the image as problem-power for research.
\end{abstract}

Palavras-chave: imagem, pescadores artesanais, etnomatemática, educação matemática

Keywords: image, artisanal fishermen, ethnomatematics, mathematics education

\section{Quando puxa um fio da rede...}

\begin{abstract}
"Não pense, mas olhe!", diz Wittgenstein (I.F.§ 66), referindo-se à multiplicidade de fato, que deve ser assumido em toda sua diversidade, por oposição ao pensamento unificador que adultera aquilo que toca, acreditando tornar cristal transparente o que considera ser atmosfera opaca, mas criando apenas ficções metafísicas, isto é, pseudo-problemas (MORENO, 1985, p.67).
\end{abstract}

Iniciamos este artigo com as palavras de Moreno, um influente comentador de Wittgenstein, para inspirar essa escrita como sendo um olhar possível diante dos múltiplos olhares que podemos obter ao nos envolvermos com imagens. Nesse momento, queremos realizar um exercício sensível para que possamos ser tocadas e nos permitirmos a conversar com imagens de modo a suspender os automatismos, descolarmos da unicidade da prática do olhar e das representações fixas. Nas palavras de Moreno, "a grande dificuldade reside, justamente, em sermos capazes de ver aquilo que já está diante de nossos olhos, pois perdemos, por assim dizer, a capacidade de olhar" (ibidem, p.74).

\footnotetext{
${ }^{1}$ Esta pesquisa está atrelada a um projeto maior financiado pelo CNPq. Chamada 43/2013 - Ciências Humanas, Sociais e Sociais Aplicadas. Processo nº409228/2013-3.
} 
Este artigo tem como propósito articular o uso de imagens, como sendo um dispositivo $^{2}$, para potencializar o pensamento e problematizações quando se pesquisa no campo da Educação Matemática, mais especificamente na Etnomatemática numa perspectiva pós-estruturalista. Buscamos pensar com imagens para constituir subjetividades e saberes na prática de pesquisar, mas não de forma a engessar e remeter a ideia de conclusão. Em outras palavras, buscamos pensar com imagens para potencializar o processo de pesquisa, mestrado em andamento, que está situado na Etnomatemática com o olhar direcionado para a forma de vida dos pescadores artesanais.

Lançamos a rede ao encontro de possíveis jogos de linguagem entre pescadores artesanais potencializados por imagens. Nesse momento, "quando olhamos, sem pensar, à nossa volta, e constatamos que há múltiplas manifestações diferentes de linguagens, complexamente imbricadas com vários tipos de atividades" (MORENO, 1985, p.71), escolhemos algumas obras do pintor Rodrigo Dias Pereira ${ }^{3}$ para compor o cenário onde operam diferentes manifestações desta forma de vida.

Nossa intenção é nos permitir transitar pelo território da Imagem $^{4}$ de modo a realizar interlocuções com as ferramentas teóricas de Ludwig Wittgenstein e Michel Foucault. Para tecermos alguns entendimentos envolvendo a imagem como potência problematizadora para a pesquisa nos apoiaremos nas noções wittgenstenianas de forma de vida, jogos de linguagem, regras de significação, semelhanças de família e nas noções foucaultianas de dispositivo e poder-saber.

Na primeira parte do texto, buscamos os pensamentos wittgensteinianos, da obra de maturidade Investigações Filosóficas, e os pensamentos foucaultianos. A partir disso ilustraremos como estas ideias se entrelaçam no nosso exercício de pensar com imagens, e no processo de pesquisa. Na segunda parte do texto, vamos discorrer sobre

\footnotetext{
${ }^{2}$ Estamos considerando o conceito de dispositivo a luz de Michel Foucault que será abordado adiante.

${ }^{3}$ Rodrigo Dias Pereira se situa na trama de diferentes culturas. Nasceu no Chile na efervescência política dos anos 60 durante o exílio de seu pai José Francisco Pereira que era ativista político na época da ditadura e renomado jornalista de Florianópolis/SC. Em 1980, Rodrigo retornou ao Brasil e estudou arquitetura e artes plásticas em São Paulo. Foi somente em 2001, que ele retorna a Florianópolis onde transborda seus pensamentos e inspirações a pintar os elementos culturais desta ilha. O pintor se identifica como catarinense, manezinho e apaixonado pela Ilha da Magia e suas peculiaridades.

${ }^{4}$ Consideramos a Imagem como um campo de saber em que para abordá-la existem diferentes perspectivas de pesquisa. Nossa intenção não é adentrar nessas considerações, mas caminhar pela exterioridade. Para mais informações consultar: FLORES,C.R; WAGNER,D.R; BURATTO, I.C.F. Pesquisa em visualização na educação matemática: conceitos, tendências e perspectivas. Educação Matemática Pesquisa. São Paulo, n. 1, v.14, p.31-45, 2012.
} 
esse exercício a partir das obras de Rodrigo Dias Pereira que fizeram parte da exposição Sobre a terra, sobre o mar $^{5}$.

\section{Nas malhas emaranhadas de Wittgenstein e Foucault}

Para compreender um pouco mais sobre o posicionamento de Wittgenstein e Foucault vamos nos remeter a uma breve digressão envolvendo a virada linguística, movimento com o qual os dois nomes são referenciados por seus atos de rebeldia contra o modelo de racionalidade da modernidade.

A virada linguística ocorreu em várias áreas do conhecimento como Filosofia, Ciência, Antropologia, Arte, etc. Direcionamos nosso olhar para ilustrar alguns acontecimentos desencadeados pela Filosofia, enfatizando a linguagem. Já no século XIX, pensadores como Kiergaard, Freud, Marx e Nietzsche iniciaram questionamentos sobre os efeitos provocados pelo modelo de razão determinado pela modernidade. $\mathrm{O}$ movimento foi intensificado no século $\mathrm{XX}$ em que desencadeia diversas problematizações acerca dos modelos tradicionais da filosofia envolvendo questões epistemológicas, éticas, estéticas e políticas. Assim, inicia o processo de desconstrução da própria filosofia.

Nesse momento, "o homem moderno perde novamente seu referencial" (CONDÉ, 2004, p.18), pois enfrenta um processo de “descentramento" levando-o à crise da razão. Essa crise mostra-se, principalmente, a partir da falência da ideia de fundamentação última do conhecimento. Além disso, a sociedade passa a conviver com suspeitas quanto aos próprios limites e possibilidades da racionalidade (CONDÉ, 2004). Assim, a modernidade é atravessada por um movimento de estranhamento e desnaturalização do modelo até então vigente.

Para Wittgenstein a virada linguística proporciona "uma luta contra o enfeitiçamento de nosso intelecto pelos meios da linguagem" (WITTGENSTEIN, 2014, p.71, §109). Ao passo que "uma imagem mantinha-nos prisioneiros. E não podíamos escapar, pois ela residia em nossa linguagem, e esta parecia repeti-la para nós, inexoravelmente" (ibidem, p.72, §115). A filosofia ficou a suspeita de que "expõe tudo

\footnotetext{
${ }^{5}$ A exposição Sobre a terra, sobre o mar foi apresentada na Galeria de Arte Martinho de Haro localizada na Câmara Municipal de Florianópolis/SC no ano de 2012. Para mais informações sobre a exposição completa acessar: <http://www.cmf.sc.gov.br/galeria-de-artes>. Acesso em 17. jun. 2014. As obras também estão disponíveis em <http://tramadascores.blogspot.com.br/> Acesso em : 17. jun. 2014.
} 
e não esclarece, nem deduz nada" (ibidem, p.75, §126) impulsionando assim, a ruptura de muitos filósofos com o modelo da modernidade.

Ocorre portanto, o abandono do conhecimento como representação e se insere a ideia de que o conhecimento é uma prática social. Os pensadores como Davidson, Kuhn, Rorty e o Segundo Wittgenstein passam a concordar que

não é possível qualquer (tipo de) pensamento e conhecimento que não esteja sempre comprometido com a posição daquele que pensa, conhece e fala; é impossível pensar, conhecer e falar independentemente de agenciamentos, interesses, valores e forças sociais (VEIGA-NETO e LOPES, 2007, p.21).

Desse modo, "o pensamento e o conhecimento não espelham, numa mente, uma suposta realidade que estaria fora e independente dessa mente; ao contrário, toda forma de pensamento e conhecimento é, necessariamente, uma relação entre mente e coisa" (ibidem, p. 22). Essa relação está interligada a cada forma de vida constituída pelos seus jogos de linguagem específicos.

Ademais, a linguagem passa a ser não-representacional de modo que

\begin{abstract}
não depende de nenhum suposto princípio transcendente a guiá-la; ela não depende de nenhum impulsionador trans-histórico, de nenhum motor metatemporal e metaespacial; ela não precisa de nenhum atrator teleológico que ficasse à espera, no futuro, para ser atingido ou realizado. É isso que quizeram dizer Nietzsche e Foucault quando dispensaram qualquer a priori, exceto o a priori histórico: nada há nem por fora, nem antes, nem para além das sequências temporais imediatas de tudo o que acontece (VEIGA-NETO e LOPES, 2007, p. 25).
\end{abstract}

Em outras palavras, não há uma linguagem por trás de outra linguagem que carregue consigo uma essência. Há apenas o que é dito constituído pelas formações históricas, políticas, sociais e culturais que oferece condições de possibilidades para dizer e compreender sobre as coisas do mundo. "O que está oculto, não nos interessa" (WITTGENSTEIN, 2014, p. 75, § 126).

Segundo Bello (2010) a partir dos pressupostos da virada lingüística é possível afirmar que "a realidade é linguisticamente construída", pois se insiste que o significado dos objetos materiais ou sociais não estaria nos objetos em si, mas na construção lingüística que os define. Acrescenta ainda que, o posicionamento está em

não assumir a linguagem numa perspectiva totalizadora ou de princípio fundamental e único de inteligibilidade, mas desconstruí-la como mediação privilegiada entre nós e o mundo; assumi-la como uma das condições de possibilidade e de existência das formas de vida, do mundo, das subjetividades (BELLO, 2010, p. 550). 
Assim, um modo de pensar as coisas do mundo é constituído na e pela linguagem. Considerando a variedade de jogos de linguagem pode-se afirmar a existência de diferentes maneiras de dizer e ver a realidade em conformidade com as diversas formas de vida.

Diante dessas considerações sobre o posicionamento desencadeado pela virada linguística, passamos a enfatizar os pontos de aproximação entre Wittgenstein e Foucault em relação à linguagem. Segundo Veiga-Neto (2011, p.90-91), os filósofos "dão as costas para a busca de uma suposta razão pura e voltam-se para a análise das relações da linguagem consigo mesma e das relações entre a linguagem e o mundo". Mesmo que situados em problemáticas distintas ambos se interessavam pela filosofia analítica pragmática de modo a realizar a análise do significado dos enunciados diante do contexto do seu uso. Desta forma, Wittgenstein e Foucault abandonam a crença de que uma linguagem que seria capaz de representar o mundo.

Wittgenstein, em sua obra de maturidade Investigações Filosóficas, considera que "representar uma linguagem [em seu sentido quotidiano] equivale a representar uma forma de vida" (WITTGENSTEIN, 2014, p. 23, § 19). Assim, é na e pela linguagem que produzimos significações sobre as coisas do mundo constituindo, portanto, os diferentes jogos de linguagem que abarcam não apenas a língua, mas também as ações.

Os jogos de linguagem de diferentes formas de vida podem ou não apresentar semelhanças de família entre si. Condé (2004, p. 57) afirma que "ainda que uma semelhança de família possibilite analogias, ela também permite perceber as diferenças. E é dentro desse jogo de semelhanças e diferenças que nos situamos, estabelecendo nossa racionalidade". Sendo assim, será possível estabelecermos semelhanças e diferenças entre os jogos de linguagem da forma de vida dos pescadores artesanais e a forma de vida da matemática escolar.

A concepção de linguagem apresentada por Wittgenstein é constituída a partir da significação determinada ao uso que fazemos das palavras (CONDÉ, 2004). Isto é, a produção de significados está atrelada ao uso nos jogos de linguagem realizado por cada forma de vida. Tal uso "não é uma prática indiscriminada, ainda que relativamente livre, ele é regido por regras que distinguem o uso correto do incorreto das palavras" (Ibidem, p.89).

Wittgenstein denomina gramática como sendo o conjunto dessas regras que são dadas a partir das práticas. Segundo Condé (2004, p.84) "as regras possuem uma forma própria de funcionamento que não exige a correspondência com o mundo, mas apenas 
interações. Nesse sentido, a gramática é colocada em funcionamento a partir da prática social específica de uma forma de vida.

O pensamento de Foucault "assume a linguagem como constitutiva do nosso pensamento e, em consequência, do sentido que damos às coisas, à nossa experiência, ao mundo" (VEIGA-NETO, 2011, p.89). Desse modo, podemos considerar que somos constituídos na e pela linguagem e que somos atravessados, a todo o momento, pelos discursos dos quais participamos nas relações sociais. Assim, "os discursos não estão ancorados ultimamente em nenhum lugar, mas se distribuem difusamente pelo tecido social, de modo a marcar o pensamento de cada época, em cada lugar e, a partir daí, construir subjetividades" (ibidem, 2011, p.100).

A partir desse posicionamento da linguagem ocorrem implicações no entendimento de como se dá o conhecimento. Veiga-Neto (2011) nos diz que o conhecimento passa a ser entendido como produto de discursos cuja logicidade é construída. Assim, a prática discursiva, sendo o conjunto de enunciados, molda nossos modos de ver e de dizer sobre as coisas do mundo.

Segundo Veiga-Neto (2011) é possível inferir que os entendimentos de Foucault apresentam proximidades com a obra de maturidade de Wittgenstein. Questões como “não perguntar o que é isso?", mas sim “perguntar como isso funciona?" ou "aquilo que está oculto não nos interessa" são comuns aos dois filósofos.

Estamos inseridas nesse movimento de questionar como funciona pensar a imagem como um dispositivo que carrega consigo as variáveis: saber, poder e subjetivação. Foucault demarca dispositivo como sendo

\footnotetext{
um conjunto decididamente heterogêneo que engloba discursos, instituições, organizações arquitetônicas, decisões regulamentares, leis, medidas administrativas, enunciados científicos, proposições filosóficas, morais, filantrópicas. Em suma, o dito e o não dito são os elementos do dispositivo. $\mathrm{O}$ dispositivo é a rede que se pode estabelecer entre estes elementos (FOUCAULT, 2000, p. 244).
}

Sendo assim, o dispositivo estabelece estratégias de relações de força que sustenta os diferentes saberes e é sustentado por eles. A noção de dispositivo elaborada por Foucault foi comentada por Deleuze (1996) que nos diz que essa noção

têm por componentes linhas de visibilidade, linhas de enunciação, linhas de força, linhas de subjectivação, linhas de brecha, de fissura, de fractura que se entrecruzam e se misturam, acabando por dar umas nas outras, ou suscitar outras, por meio de variações ou mesmo mutações de agenciamento (DELEUZE, 1996, p. 85). 
Transitar por essas linhas nos proporcionará um olhar problematizador para com os regimes de verdades colocados a operar nos jogos de linguagem da forma de vida dos pescadores artesanais e do ambiente escolar.

\section{A pensar com imagens...}

Não procurarei saber a que servem as imagens e por que existem, e sim como elas existem, como vivem, como nos fazem viver. Ou ainda, quais são suas maneiras de nos fazer pensar? E chegar, desse modo, a desvendar algo da maneira como a imagem nos provoca a pensar, nos convoca a pensar (SAMAIN, 2012, p.21).

Consideramos que há muitas perspectivas de estudo envolvendo as teorizações de imagem e diferentes articulações feitas no campo da Educação Matemática, mais especificamente na relação entre Arte e Matemática ${ }^{6}$. Nesse momento, não é nossa pretensão aprofundar essas discussões. Muito embora, estamos interessadas no "fato de que toda imagem (um desenho, uma pintura, uma escultura, uma fotografia, um fotograma de cinema, uma imagem eletrônica ou infigráfica) nos oferece algo para pensar: ora um pedaço de real para roer, ora uma faísca de imaginário para sonhar" (SAMAIN, 2012. p. 22). Ao longo deste artigo, vamos utilizar a palavra imagem ao invés de pintura.

Deste modo, procuramos nos entregar a imagens que não apenas representassem pescadores (artesanais), mas também nos fizessem pensar. Transitamos por obras mundialmente, nacionalmente, regionalmente conhecidas e fomos tocadas pelas imagens do pintor Rodrigo Dias Pereira, mais especificamente as que fizeram parte da exposição Sobre a terra, sobre o mar realizada em Florianópolis/SC no ano de 2012. A escolha foi motivada, se é que podemos falar e expressar como as imagens nos tocaram, por alguns elementos sensíveis como as cores, os contornos objetivos e subjetivos, os movimentos, as possibilidades de pensamento e diálogo entre as imagens.

Cabe aqui falar um pouco sobre o sujeito pintor, falar daquele que produz a imagem com as suas linhas de visibilidade, de enunciação, de força, de subjetivação de fuga e que conversa com ela em todo seu processo de produção. Por outro lado, após a imagem ser apresentada a outros observadores, o pintor já não tem mais o controle de sua obra.

\footnotetext{
${ }^{6}$ Para mais informações consultar: FLORES,C.R; WAGNER,D.R. Um mapa e um inventário da pesquisa brasileira sobre arte e educação matemática. Educação Matemática Pesquisa. São Paulo, n. 1, v.16, p.243-258, 2014.
} 
Rodrigo afirmou em uma entrevista ${ }^{7}$ concedida ao Jornal Notícias do Dia no ano de 2011 que "hoje em dia não existe mais isso de se definir um estilo. A arte contemporânea cria infinitas possibilidades. Existe um reaproveitamento de tudo, um grande caldo em que se tem a liberdade de ousar". Esse movimento de pensamento, certamente, é expresso pelas suas obras ao despertar a atenção para as cores, os movimentos e as possibilidades de pensamento que elas provocam.

A fala do pintor é provocativa no sentido de que podemos pensá-la em relação a pensar a Etnomatemática com imagens. Afinal, pensar com imagens também é criar infinitas possibilidades entrelaçadas a liberdade de ousar, de nos permitirmos viver a experiência, no sentido proposto por Larrosa (2004), e sermos tocadas para então tecer possíveis desdobramentos para a Educação Matemática.

Passamos então, a convesar com três imagens considerando que elas dialogam entre si e apresentam alguns traços em comum. Deste modo, vamos emarranhar o texto e as pinturas num diálogo que as envolvem conjuntamente.

Queremos destacar na primeira imagem questões associadas as cores e os contornos objetivos e subjetivos, muito embora também estão presentes nas outras imagens escolhidas, de modo a costurar com nossas reflexões a cerca dos jogos de linguagem dos pescadores artesansais possibilitando um modo de olhar. Contudo, nossa intenção é deslocar de uma suposta perspectiva de Teoria das Cores, como a proposta por Goethe em 1810, e nos aproximarmos das problematizações desenvolvidas por Wittgenstein em sua obra Anotações sobre as cores em que nos provoca com a seguinte pergunta: "Como é que as pessoas aprendem o significado dos nomes das cores?" Convidamos a leitora e o leitor a observar a Imagem 1 e sentir as cores.

\footnotetext{
${ }^{7}$ A entrevista de Rodrigo Dias Pereira concedida ao Jornal Notícias do Dia (2011) está disponível em: $<$ (http://ndonline.com.br/florianopolis/plural/6908-rodrigo-pereira-expoe-telas-de-uma-ilha-reconstruidae-de-epoca-indeterminada-em-florianopolis.html)>. Acesso em: 17. jun. 2014.
} 


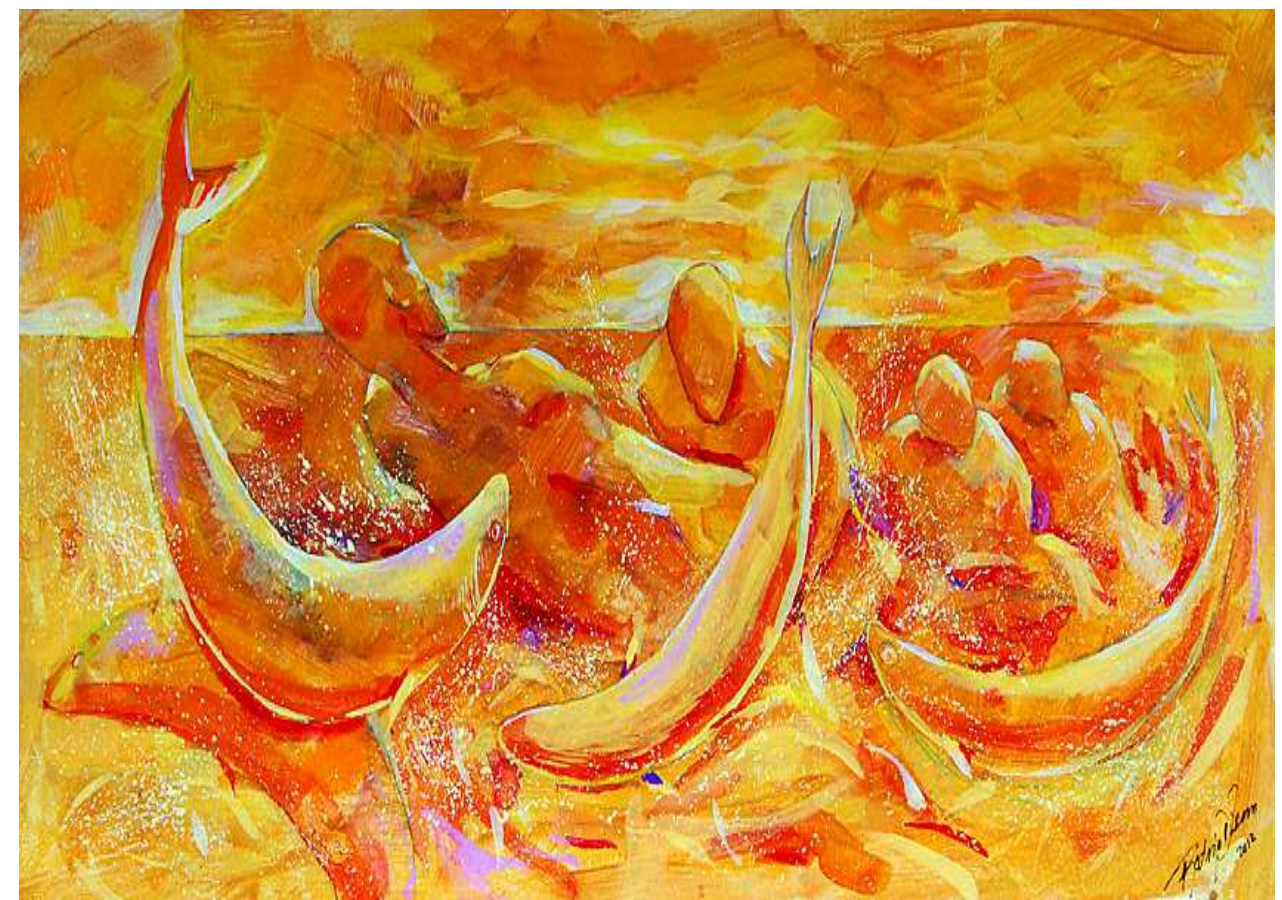

Imagem 1 - Tainha 8, Rodrigo Dias Pereira, (2012).

Fonte: Trama das Cores. Disponível em: <tramadascores.blogspot.com.br>

O posicionamento de Wittgenstein (2009) não está em querer encontrar uma teoria das cores (nem fisiológica nem psicológica), mas sim a lógica dos conceitos de cor. Desse modo, Wittgenstein faz o seguinte questionamento:

"O que significam as palavras 'vermelho', 'azul', 'preto', 'branco'[?]” podemos / decerto // bem // apontar direto para coisas assim coloreadas - mas não vai além da nossa capacidade de esclarecer estas palavras! De resto, acerca de seu emprego, nós não nos fazemos qualquer representação ou apenas uma de todo grosseira e em parte falsa (WITTGENSTEIN, 2009, p. 51).

Ocorre que "não é de modo algum claro a priori o que são os conceitos de cor / puros // simples //" (WITTGENSTEIN, 2009, p.89). Foi atribuído por assim dizer, não os significados das palavras 'vermelho', 'azul', 'preto', 'branco', mas a descrição do uso na medida em que conseguimos apontar, seguir uma tabela de cores ou participar de um jogo de linguagem. Wittgenstein acrescenta que "os conceitos de cor são de tratamento semelhante aos conceitos da sensação" (ibidem, 2009, p. 91).

Certamente em algumas formas de vida existem diferentes usos para a cor vermelho, por exemplo, em alguns casos ela é usada para desingar as sensações de calor, de paixão, de perigo. Esta cor também é utilizada para a identificação do sujeito carpinteiro na construção civil, ou como identificação dos erros cometidos em avaliações escolares. Contudo, a palavra vermelho continua 'sem significado'. 
Segundo Wittgenstein (2009, p. 81) “em filosofia, é preciso em cada caso aprender não apenas o que se pode dizer sobre um objeto, mas sim como se tem falado dele. É preciso sempre e de novo aprender o método com que se deve abordá-lo". Sendo assim, cabe a comparação quando uma criança escuta alguém falar o nome de cada cor e aponta para a tabela de cores em seguida, ela passa a repetir o processo. Podemos afirmar que a criança começa a participar dos jogos de linguagem das cores onde identifica o vermelho, azul, preto, branco, amarelo, e também o avermelhado, verdeavermelhado, amarelo-azulado, e todos os ados.

Nesse caso, somos provocadas pela Imagem 1 a saber sua cor predominante. Poderíamos dizer ser o alaranjado ou amarelado ou amarelo-avermelhado, ou dourado, ou vermelho-amarelado, ou outros ados. Mas como saber qual está correto? Segundo Wittgenstein (2009) a decisão pertence aos jogos de linguagem de cada forma de vida. Isso implica que a produção de significado está atrelada ao uso possibilitando a pluralidade dos modos de olhar.

Exercitando um pouco mais a prática de olhar, na Imagem 1, podemos perceber o grau de objetividade e subjetividade colocados juntos a operar na composição final da imagem. Muito embora, se considere aqui que não há nada por trás da imagem, mas sim aquilo que nos provocar a pensar sobre. Sendo assim, o pintor estabelece um "jogo" entre contornos definidos e subjetivos que nos desloca a discorrer sobre os pescadores artesanais, nossos sujeitos de pesquisa. Sabemos que seus contornos definidos participam de uma forma de vida marcados por suas especificidades expressas pela sua arte de pescar com o propósito de 'pegar' o peixe para a sobrevivência familiar.

Sabemos que onde há pescadores há também redes, tarrafas, canoas, embarcações, mãos marcadas e pés cansados pelo trabalho diário, no rosto sinais do tempo ao encontro do olhar de espreita a espera de avistar um cardume que vão compondo um jogo de linguagem que se fala e age pela pluralidade e combinação dos elementos lua, vento, maré, força, equilíbrio, movimento do peixe e "sorte". Nesses contornos há atravessamentos por questões sociais, econômicas, políticas que permeiam a sociedade como um todo.

No entanto, a subjetividade escapa dos contornos definidos. Ao mesmo tempo em que identificamos o sujeito pescador artesanal com suas especificidades se trata também de um sujeito de conhecimento que tem seus saberes expressos em seu corpo, nas suas ações e na fala. De modo singular, estamos interessadas em evidenciar a 
racionalidade matemática presente nos jogos de linguagem dos pescadores artesanais. Cabe ressaltar que nossa intenção não é matematizar esses saberes, não é buscar a transferência de significados, mas sim mapear os modos de calcular, medir e inferir utilizados por essa forma de vida, mesmo que não possua objetos matemáticos propriamente ditos e conhecidos.

Assim sendo, buscamos outros elementos que darão subsídios à investigação que serão abordados com a Imagem 2. A começar que a imagem nos provoca a pensar o movimento realizado na e pela forma de vida dos pescadores artesanais. Podemos salientar esse movimento expresso na sua arte da pesca realizada no balanço da água, na corrida do peixe, no lance certeiro das redes, no corpo do pescador. Por outro lado, também nos desperta a observar o movimento de seus saberes enquanto sujeitos que dominam tal prática.

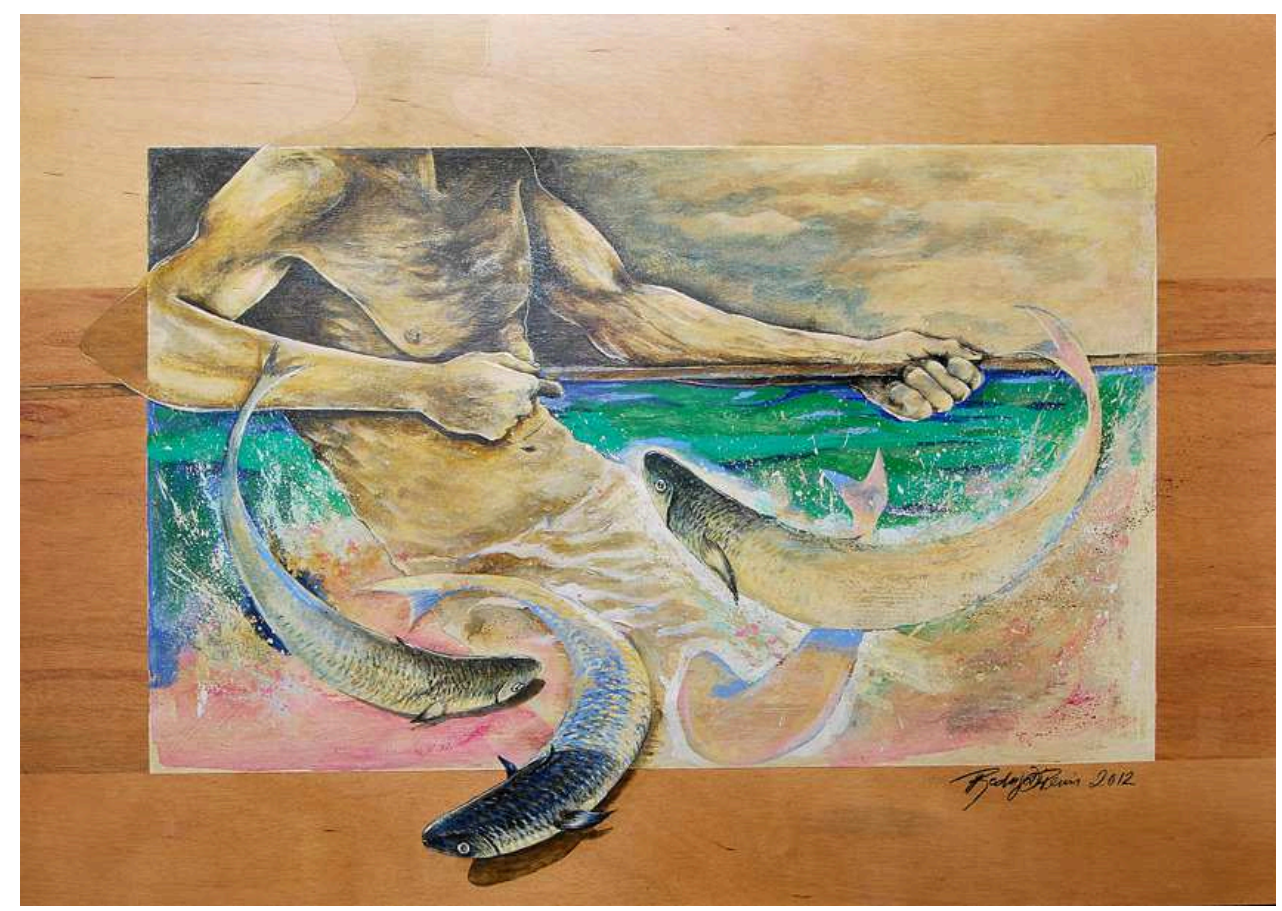

Imagem 2 - Tainha 6, Rodrigo Dias Pereira, (2012).

Fonte: Trama das cores. Disponível em: <tramadascores.blogspot.com.br>

Para compor este olhar buscamos as linhas de força que podem ser encontradas na problematização proposta por Foucault envolvendo a noção de poder-saber. Na obra Em defesa da sociedade, Foucault (1999) problematiza a insurreição dos "saberes sujeitados" designando de duas formas: 
segundo lugar, (...) eu entendo igualmente como saberes não conceituais, como saberes insuficientemente elaborados: saberes hierarquicamente inferiores, saberes abaixo do nível do conhecimento ou da cientificidade requeridos (FOUCAULT, 1999, p. 11-12).

Desse modo, Foucault (1999) afirma que a insurreição dos saberes trata de fazer que intervenham saberes locais, descontínuos, desqualificados, não legitimados, contra a instância teórica unitária que pretenderia a hierarquia dos conhecimentos e das ciências. "Tratava-se do saber histórico das lutas" (Ibidem, p.13). Esta investigação se propõe a fazer intervir os saberes dos pescadores artesanais para enfatizar os diferentes modos de pensar na prática da pesca.

Nas palavras de Foucault (2000) não é possível falar em saberes desvinculados dos poderes. O interesse desse filósofo "é o poder enquanto elemento capaz de explicar como se produzem os saberes e como nos constituímos na articulação entre ambos" (Veiga-Neto, 2011, p.56). Desse modo, as imbricações dos saberes e poderes nos permitem problematizar a politicidade do conhecimento gerando um movimento de desnaturalização de saberes que foram constituídos como verdades.

A verdade, no entendimento de Foucault, se dá pelo conjunto das regras segundo as quais se distingue o verdadeiro do falso e se atribui ao verdadeiro efeitos específicos de poder. E ainda acrescenta que cada sociedade tem seu regime de verdade com os tipos de discursos que operam como verdadeiros, os mecanismos para obtenção da verdade e o estatuto que avalia o verdadeiro do falso (FOUCAULT, 2000). Assim, pensamos discutir as verdades que atravessam a pesquisa e, em efeito politizar o conhecimento do pescador artesanal permitindo a legitimidade de seus saberes.

Ao passo que pretendemos traçar as linhas de forças que atravessam a forma de vida dos pescadores artesanais considerando questões sociais, econômicas, políticas associadas às relações de poder e produção de verdades. Ademais, traçar as linhas de fuga que remetem ao sujeito pescador como a dissolução do controle hegemônico que inicia um processo de borrar as fronteiras do conhecimento, ou seja, o sujeito pescador passa a ser um sujeito de conhecimento.

Estamos considerando o movimento como um elemento que potencializa as possibilidades de pensamento e diálogo na pesquisa com imagem. Uma potência que está em tornar-se com na qual existe a interação constante e movente entre o sujeito que olha e a imagem. Desse modo, a Imagem 3 nos remeteu aos nossos primeiros 
movimentos realizados como ensaios com pescadores artesanais do bairro Barra da Lagoa - Florianópolis/SC no qual estamos inseridas para participar dos jogos de linguagem específicos desses pescadores.

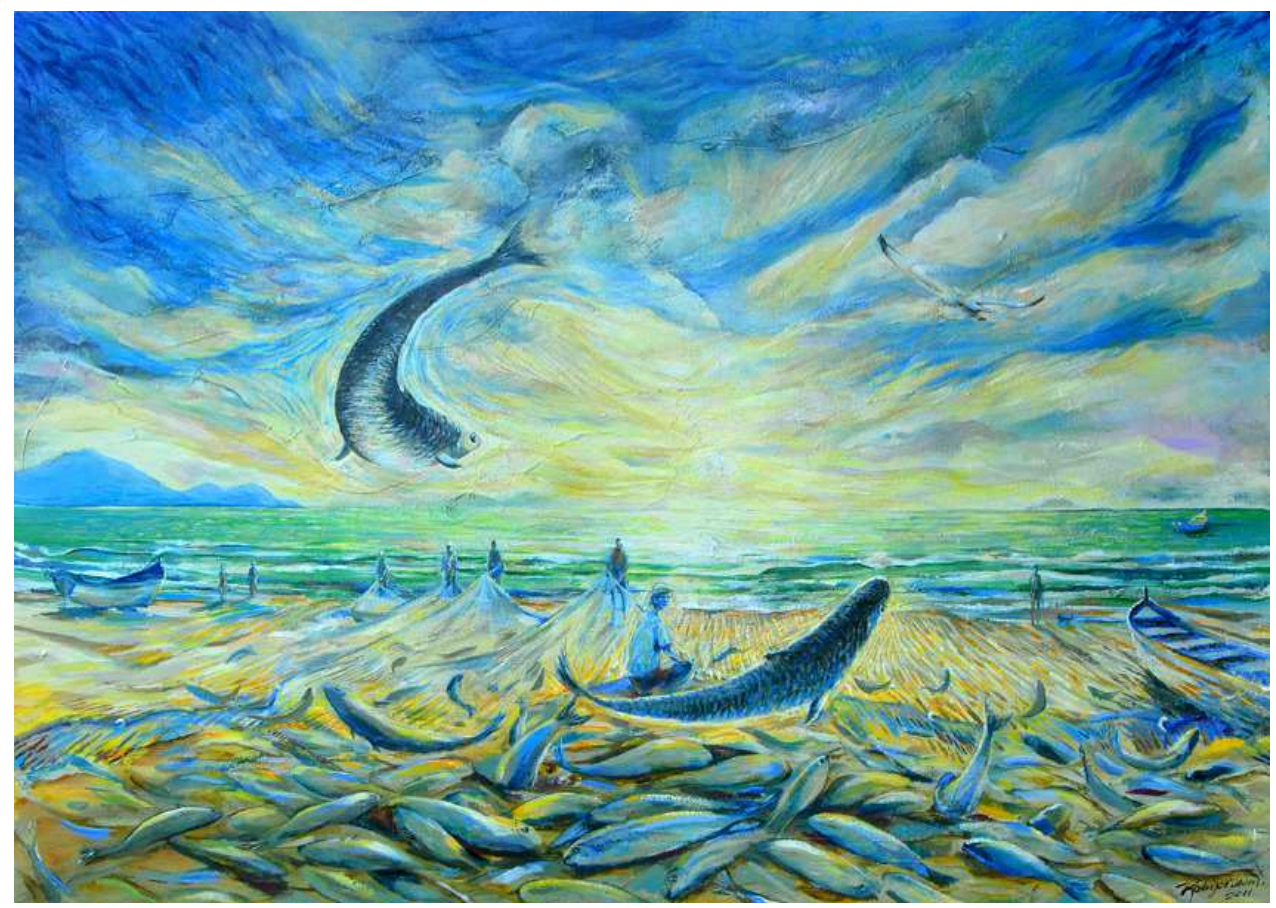

Imagem 3 - Tainha 2, Rodrigo Dias Pereira, (2011).

Fonte: Trama das cores. Disponível em: <tramadascores.blogspot.com.br>

O grupo investigado se chama Saragaço cujo nome foi dado pela descrição da agitação, o 'corre-corre' deslizando a canoa para o mar e a festa que se faz da pesca. $\mathrm{O}$ grupo é formado por pescadores artesanais nativos de diferentes idades e por outros pescadores que se juntam ao grupo na temporada da pesca da tainha.

Nesse momento de observação eles estavam organizados em vinte pescadores habilitados para a arte da pesca. Dentre eles três são olheiros que ficam em uma região mais alta da praia para observar a aproximação do cardume e avisar ao restante do grupo; sete pessoas vão à canoa sendo quatro remadores, um chumbereiro, o patrão, e um mergulhador. Os demais têm a função de ajudar na retirada dos peixes do mar e outras funções tais como cozinhar.

Os primeiros contatos nos fizeram sentir a junção de imagens 'vivas' carregadas por suas cores, movimentos e articulações. O cenário é composto pela expectativa ao avistar um cardume de tainhas, avisar o grupo e realizar um bom trabalho na retirada dos peixes.

Alguns pontos começam a emergir entre eles a racionalidade matemática utilizada na divisão dos peixes. Determinada pelo seguinte jogo de linguagem: Os 
peixes são retirados do mar e levados a praia para fazer a contagem. Em seguida, dividem os quinhões dos quais um quinhão será dividido entre os donos e o outro quinhão entre os pescadores dependendo de sua função e tempo de serviço no grupo. Os pescadores ainda por costume doam alguns peixes para a comunidade que junto festeja a safra realizada.

Um segundo ponto está na divisão do mar ao considerarem um espaço de todos e que assim, oportuniza quem do mar e da pesca gostar. A primeira divisão está baseada no calendário de modo que todas as atividades realizadas, por exemplo, surf, uso de Jet Ski ficam suspensas na temporada da tainha. Tal divisão já gerou muitos conflitos que estão sendo atenuados com o passar do tempo. A segunda divisão é realizada entre os próprios pescadores e seus respectivos grupos. Assim, algumas bandeiras pretas são colocadas no mar para demarcar a área. A terceira divisão já costumeira se dá em relação aos pescadores artesanais e industriais. Evidenciando assim, um mesmo espaço dividido temporalmente.

Segundo o depoimento de um pescador "a pesca é uma espera. Não é todo dia, varia o tempo, lua, vento, maré". Ousamos dizer que a pesquisa também se dá em um tempo de ficar à espreita e atenta as suas variações. Desse modo, continuaremos sendo provocadas a pensar com as imagens "vivas" presentes em nosso território de investigação.

\section{As imagens conversam entre si, conversam conosco...}

Ao realizar este exercício sensível de pensar com imagens podemos perceber que ao mesmo tempo em que as imagens conversam entre si elas também dialogam conosco. Podemos afirmar que participamos desse jogo em que há a relação de que quando olhamos para a imagem ela também nos olha e elas mesmas se olham entre si. $\mathrm{O}$ jogo de linguagem empregado pelo pintor torna-se aparentado com nosso jogo de linguagem, pois ativamos os rastros da memória e nos sentimos provocadas pelas imagens ao entrelaçar produções de significados com elas.

Dessa maneira, inferimos que a imagem constitui um regime de saber que nos gera a vontade de saber de modo que nos leva a evidenciar os enunciados e as visibilidades daquele que olha. Assim, a imagem pode ser considerada como produção de conhecimento. 
Ao olhar para as imagens envolvendo os pescadores artesanais podemos potencializar o pensamento de modo a problematizar os elementos que permeiam essa forma de vida. Essas imagens vão além de representar o sujeito pescador na sua arte da pesca e sua relação com o peixe, elas nos instiga a ultrapassar as fronteiras do imediato sensível e nos conduz as suas linhas de enunciações e visibilidades. Isso tudo nos desloca a continuar perguntando: Como se engendram os saberes dos pescadores artesanais e os saberes matemáticos escolares?

\section{Referências}

BELLO, S.E.L. Jogos de linguagem, práticas discursivas e produção de verdade: contribuições para a educação (matemática) contemporânea. ZETETIKÉ: Revista de Educação Matemática, v. 18, Número Temático, p. 545-587, 2010.

CONDÉ, M. L. L. As teias da Razão: Wittgenstein e a crise da racionalidade moderna. Belo Horizonte: Argvmentvm, 2004.

DELEUZE, G. O que é um dispositivo? In: DELEUZE, G. O mistério de Ariana. Lisboa:Vega, 1996, p.83-96,

FLORES, C.R; WAGNER, D.R. Um mapa e um inventário da pesquisa brasileira sobre arte e educação matemática. Educação Matemática Pesquisa, v.16, n.1, p.243-258, 2014.

FLORES, C.R; WAGNER, D.R; BURATTO, I.C.F. Pesquisa em visualização na educação matemática: conceitos, tendências e perspectivas. Educação Matemática Pesquisa, v.14, n.1, p.31-45, 2012.

FOUCAULT, M. Em defesa da sociedade: curso no Collège de France (1975-1976). São Paulo: Martins Fontes, 1999.

Microfísica do poder. Rio de Janeiro: Graal, 2000.

LARROSA, J. Ensaios Eróticos - Experiência e paixão. In: Linguagem $e$ Educação depois de Babel. Belo Horizonte: Autêntica, p.151-165, 2004.

MORENO, A.R. Wittgenstein: ensaio introdutório. Rio de Janeiro: Taurus Editora, 1985.

PEREIRA, R.D. Trama das cores. Florianópolis. Disponível em: $<$ (http://tramadascores.blogspot.com.br/)>. Último acesso em: 17. jun.14

SAMAIN, E. (Org). As imagens não são bolas de sinuca. In: (Org). Como pensam as imagens. Campinas, SP: Editora da Unicamp, 2012, p. 21-36.

VEIGA-NETO, A.; LOPES, M. C. Identidade, cultura e semelhanças de família: as contribuições da virada lingüística. In: BIZARRO, R. (Org.). Eu e o outro: Estudos 
Multidisciplinares sobre. Identidade(s), Diversidade(s) e Práticas Interculturais. Porto: Areal, 2007, p.19-35.

VEIGA-NETO, A. Foucault e a Educação. Belo Horizonte: Autêntica, 2011.

WITTGENSTEIN, L. Investigações Filosóficas. Petrópolis, RJ: Vozes, 2014. Anotações sobre as cores. Campinas, SP: Editora da Unicamp, 2009.

JUCIARA GUIMARÃES CARVALHO. Mestranda pelo Programa de PósGraduação em Educação Científica e Tecnológica da Universidade Federal de Santa Catarina (UFSC). Participante do grupo de Pesquisa em Educação Matemática e Contemporaneidade (GeEMCo - UFSC). Integrante do Projeto de Pesquisa: Etnomatemáticas do campo de Santa Catarina (SC) e Rio Grande do Sul (RS): agricultores familiares e pescadores artesanais, com financiamento do CNPq. Chamada 43/2013 - Ciências Humanas, Sociais e Sociais Aplicadas. Processo nº409228/2013-3.

CLAUDIA GLAVAM DUARTE. Doutora em Educação pela Universidade do Vale do Rio dos Sinos (UNISINOS). Professora e coordenadora do curso de licenciatura em Educação do Campo: Ciências da Natrureza da Universidade Federal do Rio Grande do Sul (UFRGS) - Campus Litoral Norte. Coordenadora do grupo de Pesquisa em Educação Matemática e Contemporaneidade (GeEMCo - UFSC). Tem experiência na área de Educação, com ênfase em Metodologia do ensino da matemática, atuando principalmente nos seguintes temas: Etnomatemática, Currículo, Cultura e Educação Matemática.

Recebido: 30 de novembro de 2014

Revisado: 18 de fevereiro de 2015

Aceito: 07 de março de 2015 